\title{
Aspartate Aminotransferase Level as a Prognostic Marker in Acute Zinc Phosphide Poisoning
}

\author{
Bharath Prasad.S', Krupanidhi Karunanidhi', Vishnu Manohar', Naveen Mohan', Sreekrishnan T.P', Gireeshkumar K.P1', T.S. Sreenath Kumar² \\ 'Department of Emergency Medicine, Amrita Institute of Medical Sciences and Research Center; Amrita Vishwa Vidyapeetham, Kochi, India \\ ${ }^{2}$ Department of Emergency Medicine, Narayana Hrudyalaya Hospital, Narayana Health, Bangalore, India
}

\begin{abstract}
Aim: To identify whether hepatic enzyme levels can be used as a clinical predictor for mortality in patients presenting with acute zinc phosphide poisoning.

Materials and Methods: A retrospective analysis of all acute zinc phosphide poisoning cases that had presented to our emergency medicine department within the past 5 years was performed. Statistical significance of the hepatic enzyme value to the outcome of poisoning was investigated.

Results: The average age of the cases was 23.6 years. Overall, $53.3 \%$ were females, and $35.5 \%$ of the total cases were married. A total of $75 \%$ patients developed bleeding manifestations and $53.3 \%$ had encephalopathy during the course. Overall, $64.4 \%$ patients had hypotension and required inotropic support. Renal failure was seen in $48.8 \%$ cases. Within 72 h, $60 \%$ cases had high anion gap non-compensated metabolic acidosis. An AST cut-off value of 1061 units/L was identified using an ROC curve, and its association to outcome was calculated and was shown to be significant ( $p=0.001)$. The mean ALT level for outcome was calculated and was found to be significant $(\mathrm{p}=0.001)$. The mean ALT value at mortality was $982.19 \pm 85.2$ units/L.

Conclusion: Absence of an antidote and rapid onset of MODS causes high mortality rate in acute zinc phosphide poisoning. From our study, we can suggest that in patients with hepatic involvement due to acute zinc phosphide poisoning, an AST value greater than 1061 units/L on the fifth day post-ingestion of the compound is an independent predictor for mortality. (Eurasian J Emerg Med 2016; 15: 39-43)
\end{abstract}

Keywords: AST, zinc, poisoning, emergency department, hepatic failure

\section{Introduction}

It has been documented that some form of poisoning is responsible for more than one million illnesses worldwide annually in one way or the other. This is just an estimate as most cases of poisoning actually go unreported, particularly in Third World countries (1). Self-poisoning has reached epidemic proportions and has become a major public health issue in parts of the developing world $(2,3)$. Based on the limited data, it is estimated that 220,000 deaths occur worldwide annually, and majority of these deaths are intentional (4).

Zinc phosphide is a dark-grey, crystalline compound and is a highly effective rodenticide that is commonly used in the agricultural sector by mixing with food as bait (3). Phosphides are normally found as powders or pellets, usually as zinc or aluminum phosphide $\left(Z n_{3} P_{2}\right.$ and AIP); calcium and magnesium phosphide salts are also available. Acute poisoning can be direct (by ingestion of the salt) or indirect [by accidental inhalation of phosphine gas $\left(\mathrm{PH}_{3}\right)$ generated during its use]. Because zinc phosphide is cheap and is widely used in our region, its use as a suicidal agent is also increasing (5).
Orally taken zinc phosphide reacts with water and acid in the stomach and produces phosphine gas, which accounts for a large part of the observed toxicity. Being an extremely toxic gas, it irritates the respiratory tract and also causes severe systemic toxicity (6). It disrupts mitochondrial function by blocking the cytochrome $\mathrm{C}$ oxidase enzyme and increases free radical generation, resulting in lipid peroxidation and producing energy failure in cells (7). Phosphides produce rapid toxicity within $30 \mathrm{~min}$ of ingestion, and death may follow in less than $6 \mathrm{~h}$ (8). Phosphide ingestions over $500 \mathrm{mg}$ are often fatal (9).

Zinc phosphide is a potent gastric irritant; profuse vomiting and abdominal pain are often the first symptoms. Respiratory complaints could be tachypnea, dyspnea, and coughing and can even progress to acute lung injury over days $(3,10)$. Also non-cardiogenic pulmonary edema may develop later and should be managed aggressively by positive end-expiratory pressure ventilation (11). Tachycardia, hypotension and dysrhythmias, like atrial fibrillation, flutter, heart block and ventricular tachycardia, and fibrillation, may develop (12). Nervous system involvement can cause coma, tonic-clonic convulsions,

Correspondence to: Bharath Prasad.S e-mail: dr.sbharathprasad@gmail.com

Received: 22.02.2016 Accepted: 24.02.2016

(C) Copyright 2016 by Emergency Physicians Association of Turkey - Available online at www.eajem.com DOI: $10.5152 /$ eajem.2016.80488 
and delirium (10). Raised transaminases, hepatic failure, and severe metabolic acidosis with acute distal renal tubular acidosis have been associated with ingestion (13).

Absence of a specific antidote and rapid multi organ failure results in very high mortality. Even though rapid decontamination by the use of activated charcoal or gastric lavage with aggressive resuscitative measures according to various protocols are practiced from center to center, none of these have been proven to be effective in clinical studies.

There are significant numbers of studies detailing the effects, treatment, and prognosis of poisoning with aluminum phosphide and other rodenticides, but zinc phosphide has not been that elaborately studied. The purpose of this study was to identify whether hepatic enzyme levels can be used as a clinical predictor for mortality in patients who present with acute zinc phosphide poisoning.

\section{Materials and Methods}

\section{Study design and patients}

All cases of acute zinc phosphide poisoning, which had presented to our emergency department (ED) over the past five years (January 1, 2010-June 30, 2015) were retrospectively reviewed and analyzed.

Clinical and laboratory data of 73 patients affected by zinc phosphide and presented to our ED were analyzed. Patient files and electronic records were used to gather data. The cases were diagnosed as zinc phosphide poisoning based on history and laboratory findings. All the patients were transferred to the Critical Care department after initial resuscitation and gastric lavage in our ED. Blood samples for biochemical and hematologic determinations were sent from the ED within $1 \mathrm{~h}$ of presentation. Information was collected based on age, gender, nature of poisoning, and any delay in presentation to the hospital. All patients with hepatic involvement were identified, and the severity of poisoning was assessed based on the laboratory and clinical parameters, such as hepatic enzymes [aspartate aminotransferase (AST, normal range: 5-45 $\mathrm{U} / \mathrm{dL}$ ) and alanine aminotransferase (ALT, normal range: 5-40 U/dL)], elevated billirubin levels ( $>2 \mathrm{mg} / \mathrm{dL}$ ), deranged INR (>1.5), presence of shock, hypotension [mean arterial pressure (MAP) <60], elevated serum creatinine $(>1.4 \mathrm{mg} / \mathrm{dL})$, and alterations in arterial pH level (normal: 7.35-7.45).

\section{Exclusion criteria}

Pediatric patients (age $<18$ years) and patients who had consumed zinc phosphide by mixing with other substances or poisons (alcohol, sedatives etc) were excluded from the study. Also, patients who were diagnosed to have any concomitant liver diseases were also excluded. All chronic poisoning cases and cases presenting after $48 \mathrm{~h}$ of zinc phosphide consumption were excluded. Any patient who did not give consent or who got transferred to another facility was also excluded from the study. After applying exclusion criteria, we obtained a sample size of 45 from the initial pool of 73 patients.

\section{Statistical analysis}

The study data were analyzed using the Statistical Package for the Social Sciences (SPSS) software. Numeric data were presented as mean \pm standard deviation, frequent variables as rates. Two group comparisons for numeric variables were performed using the Student-t test, and normality analysis was performed using the Kolmog-
orov-Smirnov test. Receiver operating characteristic (ROC) analysis was performed for determening sensitivity and specificity. All the hypotheses were constructed as two tailed and an alpha critical value of 0.05 was accepted as significant.

\section{Results}

The average age in the study was 23.6 years. $53.3 \%(n=24)$ of the total were female subjects and the rest $46.6 \%(n=21)$ were male. In total, $88.8 \%(n=40)$ subjects ingested the poison in an attempt of suicide. The minimum ICU days was 5, while 15 days was the maximum, and the average ICU stay was 8.9 days.

All subjects had nausea and vomiting as initial symptoms; however, $60 \%$ had breathlessness and $48.8 \%$ had abdominal pain also as initial symptoms. All the patients had tachycardia as an early sign, whereas $75 \%$ also had tachypnea (Figure 1). A total of $75 \%$ patients developed bleeding manifestations as the disease progressed, whereas $53.3 \%$ also developed altered sensorium. Overall, $64.4 \%$ of our study group had hypotension and required inotropic support and $42.2 \%$ of them developed refractory hypotension. A total of $26.6 \%$ patients required mechanical ventilation, mainly for severe acidosis and airway protection due to decreased sensorium. On presen-

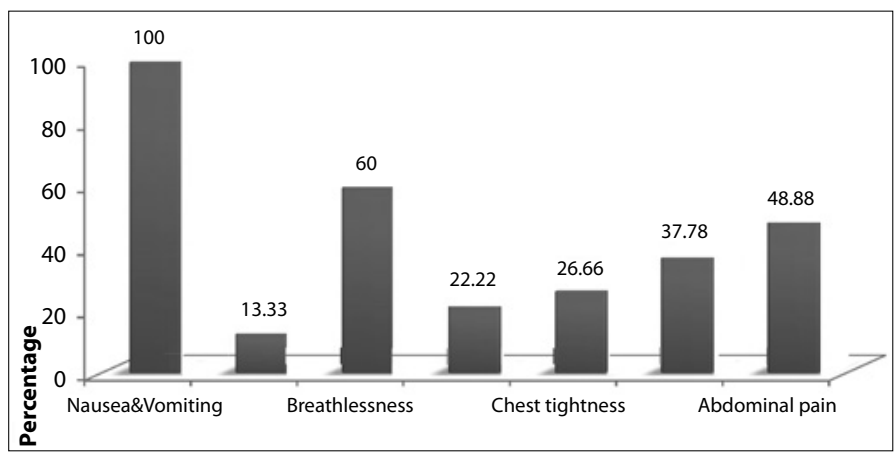

Figure 1. Common presenting symptoms in acute zinc phosphide poisoning [Frequencies of presenting symptoms are: nausea and vomiting (45); diarrhea (6); breathlessness (27); dyspnea (10); chest tightness (12); palpitation (17); and abdominal pain (22)]

Table 1. Significant factors due to acute zinc phosphide poisoning for the mortality according to univariate analysis test.

\begin{tabular}{|l|c|c|c|}
\hline Category & $\begin{array}{c}\text { Frequency } \\
\text { n (\%) }\end{array}$ & $\begin{array}{c}\text { Mortality } \\
\text { n (\%) }\end{array}$ & p \\
\hline Tachycardia & $45(100)$ & $21(46.6)$ & - \\
\hline Tachypnea & $34(75)$ & $17(50)$ & - \\
\hline Mechanical ventilation & $12(26.6)$ & $8(66.6)$ & - \\
\hline Hyperbillirubinemia & $40(88.9)$ & $20(50)$ & - \\
\hline Hypoglycemia & $25(55.5)$ & $10(45.5)$ & 0.059 \\
\hline Hypotension* & $29(64.4)$ & $19(65.5)$ & 0.001 \\
\hline Coagulopathy* & $34(75)$ & $21(61.8)$ & $<0.001$ \\
\hline Encephalopathy* & $24(53.3)$ & $17(70.8)$ & 0.001 \\
\hline Metabolic acidosis* & $39(86.6)$ & $21(53.8)$ & 0.023 \\
\hline Renal failure & $22(48.8)$ & $13(59.1)$ & 0.139 \\
\hline *Variables that showed significance in the univariate analysis. \\
\hline
\end{tabular}


tation, 17 (37.7\%) had respiratory alkalosis in ABG, but within $72 \mathrm{~h}, 27$ $(60 \%)$ cases developed non-compensated high anion gap metabolic acidosis (Table 1).

Of the 45 cases, $11.2 \%$ had mild, moderate, or severe hepatic failure-each involving $13.3 \%$ cases, respectively-and $62.2 \%$ developed fatal liver injury in accordance with the Drug Induced Liver Injury Network (DILIN) grading scale. The grade fatal consists of mortality due to liver injury and patients who required transplant. Essentially, all fatal grade patients had developed severe hepatic failure but their outcome was different.

In most patients, derangements in LFT and RFT values were apparent only after $72 \mathrm{~h}$ of ingestion. All cases had raised liver function tests by $72 \mathrm{~h}$ post-ingestion. Of the $15(33.3 \%)$ who showed elevation of AST/ALT within $24 \mathrm{~h}$ of ingestion, 8 (53.3\%) dies while the rest 7 $(46.6 \%)$ had to undergo hepatic transplantation. Renal failure and hyperbillirubinemia were seen by the 5th-6th day of ingestion of poison, while $60 \%$ of cases developed acidosis within $72 \mathrm{~h}$.

Mortality in the study was $46.6 \%(n=21)$. Of the $53.3 \%$ who survived, $29.1 \%$ required liver transplant. Also, none who underwent transplantation developed mortality.

On univariate analysis of variables, hypotension, coagulopathy, encephalopathy, and metabolic acidosis were found to be significant factors for mortality (Table 1).

An AST cut-off value of 1061 units/L was identified using the ROC curve; it had a sensitivity of $70.8 \%$ and specificity of $80.8 \%$ (Figure 2). The association of AST cut-off value and outcome was performed and was found to be significant $(p=0.001)$ (Table 2).

The mean ALT level was calculated and was found to be significant for the outcome. The mean ALT values for survival and mortality were found to be $590.33 \pm 475.73$ units/L and $982.19 \pm 85.2$ units/L, respectively $(p=0.001)$ (Table 3$)$.

\section{Discussion}

Almost all around the globe, phosphide is commonly used for suicide attempts by the younger productive age group of society (14). In previous studies, the mean age of patients involved have been described as being from 27 years to 40 years; the general notion is that patients in their third decade of life are more prone to suicide (15). In this study, the mean age was 23.6 years, even though lower, it is still comparable to earlier literature. The incidence of attempted suicide in this study was only slightly greater in females than males; while the increased incidence of poisoning in females has been described by various studies, the cause of increased male incidence can be attributed to adaptation issues to social life and financial difficulties, both of which increase the possibility of depression (15-17). Like others, we also found sex to be a non-significant factor for mortality.

The onset of clinical signs and symptoms following ingestion is highly variable, but averages within $4 \mathrm{~h}(15,18)$. Proudfoot et al. (19) reported that, usually systemic toxicity is noticed within a short interval after the ingestion. Phosphine acts as a strong reducing agent capable of inhibiting cellular enzymes involved in several metabolic processes, causing the failure of organ systems (20). Metabolic acidosis indicates a moderate to severe degree of poisoning as per Proudfoot et al's study (19). Severe metabolic acidosis alone or in association with acute respiratory alkalosis, is very common (19). In one study by Mathai et al. (14), the mean $\mathrm{pH}$ on admission was found to be $7.20 \pm 0.14$ and the mean bicarbonate concentration was $12.3 \pm 5.45$

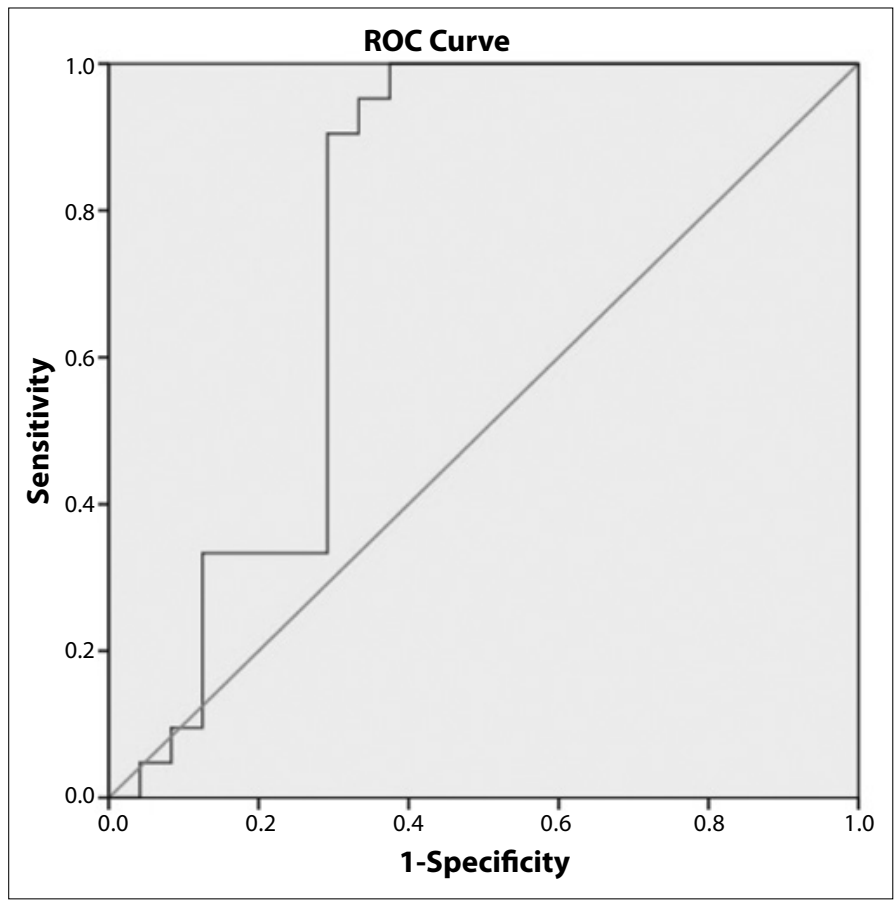

Figure 2. ROC curve of AST cut-off value: 1061 units/L; Sensitivity 70.81\%; Specificity $80.95 \%$; Accuracy $-75.6 \%$ Possitive predictive value $-81 \%$; Negative Predicitve Value $-70.8 \%$

Table 2. Correlation between AST and the outcome

\begin{tabular}{|c|c|c|c|c|}
\hline \multirow[b]{2}{*}{ Factor } & \multirow[b]{2}{*}{ Category } & \multicolumn{2}{|c|}{ Outcome } & \multirow[b]{2}{*}{$\mathbf{p}$} \\
\hline & & $\begin{array}{c}\text { Mortality } \\
\text { n (\%) }\end{array}$ & $\begin{array}{c}\text { Survival } \\
\text { n (\%) }\end{array}$ & \\
\hline \multirow{2}{*}{$\begin{array}{l}\text { AST Cut off } \\
\text { Value }\end{array}$} & $<1061$ units/L & $4(19)$ & $17(81)$ & \multirow[t]{2}{*}{0.001} \\
\hline & $>1061$ units/L & $17(70.8)$ & $7(29.2)$ & \\
\hline
\end{tabular}

Table 3. Correlation between ALT and the outcome

\begin{tabular}{|l|c|c|c|c|c|}
\hline \multirow{2}{*}{ Factor } & Outcome & $\mathbf{n}$ & Mean & $\begin{array}{c}\text { Standard } \\
\text { deviation }\end{array}$ & $\mathbf{p}$ \\
\hline ALT & Survival & 24 & 590.33 & 475.73 & 0.001 \\
\cline { 2 - 5 } & Mortality & 21 & 982.19 & 85.2 & \\
\hline
\end{tabular}

$\mathrm{mmol} / \mathrm{L}$. In the present study, five patients (11.1\%) had low $\mathrm{pH}$ levels at admission and all developed mortality; low $\mathrm{pH}$ being the causative factor for deaths in these patients. The mean bicarbonate level in this study was $16.5 \pm 4.2 \mathrm{mmol} / \mathrm{L}$. $62.2 \%$ of cases were metabolically stable on admission, while $26.66 \%$ of patients had acute respiratory alkalosis explained by hyperventilation due to anxiety and $11.1 \%$ had compensated metabolic acidosis. Within $24 \mathrm{~h}$ of admission, metabolic acidosis increased to $66.7 \%$ from the initial $11.1 \%$. Severe metabolic acidosis was found to be a significant factor for mortality in our study, in line with others $(15,18,19)$.

Hemodynamic instability and refractory hypotension have been reported in studies (8). In our study, $64.4 \%$ of patients had hypotension and $65.5 \%$ of them developed mortality. Shock is identified as one of the significant factors for mortality in our study. Central nervous system depression may arise due to hypotension and toxins, as such or due to hepatic or other organ system failure $(18,19,21)$. A study by Louriz et al. (22) reported that mortality in acute phosphine 
poisoning (APP) correlated with shock and altered consciousness. In our study, 53.3\% of patients developed depressed sensorium at some point of treatment; while three of them who had it from presentation itself succumbed to death. $70.8 \%$ of those with depressed sensorium died, with refractory state of shock and encephalopathy due to hepatic failure being the cause of high mortality.

It has been proven that the systemic toxicity caused by phosphine is mainly to the heart, lungs, liver, gastrointestinal tract, kidney, and brain since $\mathrm{PH}_{3}$ molecules targets them particularly $(23,24)$. The effect of phosphine causing failure of the heart, lungs, and gastrointestinal tract is well studied in cases of aluminum phosphide poisoning, but the effect of it in the liver and renal parenchyma is not well studied $(12,19,21)$. Altered liver function tests (LFTs) in non-fatal cases of zinc phosphide poisoning suggest that there is some pathology targeting the liver $(24,25)$. A study in Iran reported that the liver biopsies from 37 patients who had died of zinc phosphide poisoning showed injury to hepatic parenchyma, which ranged from congestion to necrosis at different stages. The main changes found were fine cytoplasmic vacuolization of the hepatocytes and sinusoidal congestion (26-28).

Saleki et al. (26) stated that $\mathrm{PH}_{3}$ can cause liver dysfunction, especially after the first day of poisoning. All 45 patients in our study group developed altered liver function tests by the 3rd day ( $72 \mathrm{~h}$ ) of admission; 33.3\% (15) patients showed altered LFTs within $24 \mathrm{~h}$ of admission, of these $53.3 \%$ developed mortality. The rate of mortality was twice as high in patients with elevated LFTs within $24 \mathrm{~h}$ of admission when compared to those who developed derangement over $72 \mathrm{~h}$. The grading scale developed by the Drug Induced Liver Injury Network (DILIN) was used to grade the severity of liver injury due to poisoning (29). Patients were categorized into four groups of mild, moderate, severe, and fatal liver injury according to the presence of jaundice, hospitalization, signs of hepatic or other organ failure, and the ultimate outcome. According to the grading scale, out of the 45 cases, $24.4 \%$ had mild to moderate liver injury, $13.3 \%$ had severe, and $62.2 \%$ developed fatal liver injury. Clinically, $75 \%$ patients had features of severe fulminant hepatic failure like coagulopathy and altered sensorium with rapidly elevating LFTs. Coagulopathy in the form of raised INR was seen in 75\% patients-this is a new observation and has not been described in other studies as not many of these have concentrated on the hepatic manifestations of phosphide.

An ROC curve was used to find a cut-off value for AST and ALT. Values from post-ingestion at Day 3 and Day 5 were used to find the cut-off point; as there were absent data from certain patients post the fifth day of ingestion either due to discharge from hospital or death due to poisoning. An AST cut-off value of 1061 units/L was found with a sensitivity of $70.8 \%$ and specificity of $80.8 \%$. The association to outcome was calculated and was found to be a significant predictor for mortality with an accuracy of $75.6 \%$. We could not get a similar cut-off value for ALT due to the poor specificity. Hence, the mean ALT levels for survival and mortality were calculated as $590.3 \pm 475.7$ units/L and $982.1 \pm 85.2$ units/L, respectively.

Renal failure was present in $48.8 \%$ of patients in our study, of which $59 \%$ succumbed to death. $81.8 \%$ of the patients who had renal failure also had signs of shock too. The cause of renal failure can be due to phosphine or due to severe hypotension.

No antidote is available for poisoning with phosphides. The reported mortality for aluminum phosphine and zinc phosphide greatly varies across different studies, although they are generally high (21). The mortality rate in our study was $46.7 \%$.

\section{Study limitations}

Our study group included patients that were admitted to our center, and thus, represented only a small percentage of cases of zinc phosphide poisoning in our state. Unfortunately, we do not have a networked database in our country to provide more comprehensive overview of the topic.

Use of the fifth-day (post-ingestion) AST value as a predictor for mortality can help in the identification of poor prognosis patients and also in decision-making regarding the need for more aggressive treatment strategies for the prevention of mortality (e.g., hepatic transplantation).

\section{Conclusion}

Although it is a rare form of suicide attempt, the mortality rate in patients with acute zinc phosphide poisoning is very high. Absence of an antidote and rapid onset of MODS causes high mortality. Even though the presence of metabolic acidosis, refractory hypotension, cardiac failure, and hepatic failure are proven factors for mortality, there is no clear cut-off point to predict mortality. From our study, we can suggest that in patients with hepatic involvement due to acute zinc phosphide poisoning, an AST value greater than 1061 units/L on the fifth day post-ingestion of the compound is an independent predictor for mortality.

Ethics Committee Approval: Ethics committee approval for this study was excluded because it is a retrospective study.

Informed Consent: Patient consent for this retrospective study has not been received.

Peer-review: Externally peer-reviewed.

Conflict of Interest: No conflict of interest was declared by the authors.

Financial Disclosure: The authors declared that this study has received no financial support.

\section{References}

1. Singh B, Unnikrishnan B. A profile of acute poisoning at Mangalore (South India). J Clin Forensic Med 2006; 13: 112-6. [CrossRef]

2. Eddleston M. Patterns and problems of deliberate self-poisoning in the developing world. QJM 2000; 93: 715-31. [CrossRef]

3. Gökdemir MT, Kaya H, Orak M, Ustundag M, Karasu M. A rare type of suicide attempt in East Turkey: Acute zinc phosphide poisoning. Eurasian J Emerg Med 2013; 12: 76-9. [CrossRef]

4. Konradsen F, van der Hoek W, Cole DC, Hutchinson G, Daisley H, Singh S, et al. Reducing acute poisoning in developing countries--options for restricting the availability of pesticides. Toxicology 2003; 192: 249-61. [CrossRef]

5. Chomchai S. Phosphine and phosphides. In: Olson KR, editor. Poisoning and drug overdose. New York: Mc Graw Hill; 2004. p. 306-7.

6. Perry HE. Rodenticides. In: Shannon MW, Borron SW, Burns MJ, editors. Haddad and Winchester's clinical management of poisoning and drug overdose. Philadelphia, PA: Saunders - Elsevier; 2007. p. 1225-6.

7. Chugh SN, Arora V, Sharma A, Chugh K. Free radical scavengers and lipid peroxidation in acute aluminium phosphide poisoning. Indian $J$ Med Res 1996; 104: 190-3.

8. Ahmad SH, Fakhir S, Gupta S, Singh RK. Celphos poisoning. Indian Pediatr 1991; 28: 300-1. 
9. Banjaj R, Wasir HS. Epidemic aluminium phosphide poisoning in Northern India. Lancet 1988; 1: 820-1. [CrossRef]

10. Misra UK, Tripathi AK, Pandey R, Bhargwa B. Acute phosphine poisoning following ingestion of aluminium phosphide. Hum Toxicol 1988; 7: 3435. [CrossRef]

11. Lohani Shyam P, Rajendra Kumar BC, Bidur O. An epidemiological study on acute zinc phosphide poisoning in Nepal. J Nepal Health Res Council 2002; 1: 13-6.

12. Siwach SB, Singh $\mathrm{H}$, Jagdish Katyal VK, Bhardwaj G. Cardiac arrhythmias in aluminium phosphide poisoning studied by on continuous holter and cardioscopic monitoring. J Assoc Physicians India 1998; 46: 598-601.

13. Orak $M$, Ustundag $M$, Sayhan MB. Severe metabolic acidosis secondary to zinc phosphide poisoning. J Pak Med Assoc 2008; 58: 289-90.

14. Mathai A, Bhanu MS. Acute aluminium phosphide poisoning: Can we predict mortality? Indian J Anaesth 2010; 54: 302-7.

15. Kanchan T, Menezes RG. Suicidal poisoning in Southern India: gender differences. J Forensic Leg Med 2008; 15: 7-14. [CrossRef]

16. Dudley MJ, Kelk NJ, Florio TM, Howard JP, Waters BG. Suicide among young Australians, 1964-1993: an interstate comparison of metropolitan and rural trends. Med J Aust 1998; 169: 77-80.

17. Curcić M, Dadasović J. Suicide and attempted suicide with rodenticides from 1968 to 2000. Med Pregl 2001; 54: 256-60.

18. Chugh SN, Aggarwal HK, Mahajan SK. Zinc phosphide intoxication symptoms: analysis of 20 cases. Int J Clin Pharmacol Ther 1998; 36: 406-7.

19. Proudfoot AT. Aluminium and zinc phosphide poisoning. Clin Toxicol 2009; 47: 89-100. [CrossRef]
20. Chugh SN, Arora V, Sharma A, Chugh K. Free radical scavengers \& lipid peroxidation in acute aluminium phosphide poisoning. Indian J Med Res 1996; 104: 190-3.

21. Wahab A, Zaheer MS, Wahab S, Khan RA. Acute aluminium phosphide poisoning: an update. Hong Kong J Emerg Med 2008; 15: 152-5.

22. Louriz M, Dendane T, Abidi K, Madani N, Abouqal R, Zeggwagh AA. Prognostic factors of acute aluminum phosphide poisoning. Indian J Med Sci 2009; 63: 227-34. [CrossRef]

23. Sogut O, Baysal Z, Ozdemir B. Acute pulmonary edema and cardiac failure due to zinc phosphide ingestion. J Emerg Med 2011; 40: 117-8. [CrossRef]

24. Sudakin DL. Occupational exposure to aluminium phosphide and phosphine gas? A suspected case report and review of the literature. Hum Exp Toxicol 2005; 24: 27-33. [CrossRef]

25. Shadnia S, Rahimi M, Pajoumand A, Rasouli MH, Abdollahi M. Successful treatment of acute aluminium phosphide poisoning: possible benefit of coconut oil. Hum Exp Toxicol 2005; 24: 215-8. [CrossRef]

26. Saleki S, Ardalan FA, Javidan-Nejad A. Liver histopathology of fatal phosphine poisoning. Forensic Sci Int 2007; 166: 190-3. [CrossRef]

27. Khurana V, Gambhir I, Kishore D. Microangiopathic hemolytic anemia following disseminated intravascular coagulation in aluminum phosphide poisoning. Indian J Med Sci 2009; 63: 257-9. [CrossRef]

28. Karanth S, Nayyar V. Rodenticide-induced hepatotoxicity. J Assoc Physicians India 2003; 51: 816-7.

29. Severity grading in drug induced liver injury; Available at: www.livertox. nihs.gov. a. - Variables which showed significance in univariate analysis. 